\title{
Mast Cells in Human Cutaneous Neurofibromas: Density, Subtypes, and Association with Clinical Features in Neurofibromatosis 1
}

\author{
Roope A. Kallionpääa Kaisa Ahramo ${ }^{a}$ Eija Martikkala ${ }^{a} \quad$ Elnaz Fazelia \\ Pekka Haapaniemi $^{\mathrm{b}}$ Anne Rokkab ${ }^{\mathrm{llm}}$ Leivo $^{\mathrm{a}, \mathrm{c}}$ Ilkka T. Harvima ${ }^{d}$ \\ Juha Peltonen $^{\mathrm{a}}$ Sirkku Peltonen ${ }^{\mathrm{e}} \mathrm{f}, \mathrm{g}, \mathrm{h}$
}

anstitute of Biomedicine, University of Turku, Turku, Finland; b Turku Bioscience Centre, University of Turku and Åbo Akademi University, Turku, Finland; 'Department of Pathology, Turku University Hospital, Turku, Finland; ${ }^{\mathrm{d}}$ Department of Dermatology, Kuopio University Hospital and University of Eastern Finland, Kuopio, Finland; eDepartment of Dermatology and Venereology, University of Turku, Turku, Finland; ' Department of Dermatology, Turku University Hospital, Turku, Finland; ${ }^{9}$ Department of Dermatology and Venereology, Institute of Clinical

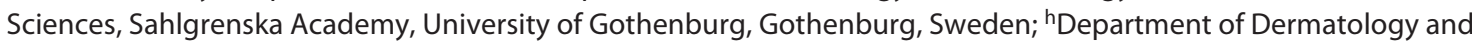
Venereology, Region Västra Götaland, Sahlgrenska University Hospital, Gothenburg, Sweden

\section{Keywords}

Chymase $\cdot$ Mast cells $\cdot$ Neurofibroma $\cdot$ Tryptase $\cdot$ Tumor microenvironment

\begin{abstract}
Background: Cutaneous neurofibromas (cNFs) are hallmarks of neurofibromatosis 1 (NF1) and cause the main disease burden in adults with NF1. Mast cells are a known component of cNFs. However, no comprehensive characterization of mast cells in cNFs is available, and their contributions to cNF growth and symptoms such as itch are not known. Methods: We collected 60 cNFs from ten individuals with NF1, studied their mast cell proteinase content, and compared the mast cell numbers to selected clinical features of the tumors and patients. The tumors were immunolabeled for the mast cell markers CD117, tryptase, and chymase, and the percentage of immunopositive cells was determined using computer-assisted methods. Results: The median proportions of positive cells were $5.5 \%$ (range $0.1-14.4$ ) for CD117, 4.0\% (1.2-7.0) for tryptase, and 5.0\% (1.1-15.9) for
\end{abstract}

karger@karger.com www.karger.com/drm

Karger $\stackrel{\text { ' }}{5}$

GOPEN ACCESS
C 2021 The Author(s).

Published by S. Karger AG, Basel

This is an Open Access article licensed under the Creative Commons Attribution-NonCommercial-4.0 International License (CC BY-NC) (http://www.karger.com/Services/OpenAccessLicense), applicable to the online version of the article only. Usage and distribution for commercial purposes requires written permission. chymase. The median densities of cells immunopositive for CD117, tryptase, and chymase were 280,243 , and 250 cells/ $\mathrm{mm}^{2}$, respectively. Small tumors, growing tumors, and tumors from patients below the median age of 33 years displayed a high proportion of mast cells. Cells expressing both tryptase and chymase were the predominant mast cell type in CNFs, followed by cells expressing chymase only. Conclusion: The results highlight the abundance of mast cells in cNFs and that their number and subtypes clearly differ from those previously reported in unaffected skin.

(c) 2021 The Author(s).

Published by S. Karger AG, Basel

\section{Introduction}

Multiple cutaneous neurofibromas (cNFs) are characteristic of neurofibromatosis type 1 (NF1). These tumors typically emerge in puberty and their number increases with age. $c N F s$ are invariably benign and rarely exceed the size of $3 \mathrm{~cm}$, yet they may be present in large numbers and cause pain, chronic pruritus, and major aesthetic and so- 
cial hindrances, which are associated with decreased quality of life $[1,2]$. In addition to cNFs, another nonmalignant tumor type typical of NF1 is plexiform neurofibroma, which can be found in about $50 \%$ of individuals with NF1. NF1 is a cancer predisposition syndrome and it is associated with various malignancies, such as those of the central and peripheral nervous system and breast [3]. The NF1 syndrome is caused by pathogenic variants of the NF1 gene [4] and it has a prevalence of $1 / 2,000$ 3,000 [5].

cNFs are thought to arise in close association with nerve tributaries of the skin [2]. All neurofibromas harbor a clonal Schwann cell population carrying a somatic second hit mutation in the NF1 gene [6]. However, the tumors also contain many other cell types, such as fibroblasts and perineurial cells, and an abundant collagenous extracellular matrix [7]. Mast cells are characteristic of cNFs [8] and they have been suggested to play a role in neurofibroma-related itch and tumor growth $[9,10]$.

Mast cells express a wide variety of surface receptors and secrete mediators, including immunomodulatory molecules, and they can regulate many other cell types such as dendritic cells, macrophages, $T$ cells, $B$ cells, and fibroblasts $[11,12]$. One of the key receptors in mast cells is CD117 (KIT) that is activated by stem cell factor (SCF). In the skin, there is a close cross-talk between mast cells and sensory nerve endings [13], which provides a potential therapeutic target for itch. In tumors, mast cells are part of the inflammatory microenvironment and may exert pro- or anti-tumorigenic effects [14].

Many mast cell functions are mediated by their serine proteinases tryptase and chymase, which can remodel extracellular matrix and activate proteins such as matrix metalloproteinase 9, procollagenase, and protease-activated receptor $2[11,14]$. Based on their proteinase content, human mast cells can be divided into different subtypes: the $\mathrm{MC}_{\mathrm{TC}}$ are rich in both tryptase and chymase, the $\mathrm{MC}_{\mathrm{T}}$ only express tryptase, and the $\mathrm{MC}_{\mathrm{C}}$ only express chymase $[15,16]$. The $\mathrm{MC}_{\mathrm{TC}}$ is the dominant type in the skin, representing approximately $99 \%$ of mast cells, while the $\mathrm{MC}_{\mathrm{T}}$ dominates in the lungs [11, 15-17]. Compared to associated benign tissues, an altered ratio of $\mathrm{MC}_{\mathrm{TC}}$ and $\mathrm{MC}_{\mathrm{T}}$ has been reported in breast [18] and lung cancer [19]. The $\mathrm{MC}_{\mathrm{C}}$ is less common [16] and was not recognized as early as the $\mathrm{MC}_{\mathrm{TC}}$ and $\mathrm{MC}_{\mathrm{T}}$ subtypes $[15,17]$. The $\mathrm{MC}_{\mathrm{C}}$ has even been suggested to represent apoptotic $\mathrm{MC}_{\mathrm{TC}}$, where the more readily soluble tryptase has diffused away, leaving cell remnants positive for chymase only $[11,18,20]$.
Murine models have highlighted the role of mast cells in plexiform neurofibromas and demonstrated that mouse Nf1-deficient tumor microenvironment and specifically $N f 1$ haploinsufficient bone marrow are essential for the formation of these tumors [21]. Although mast cells have been extensively studied in murine models of plexiform neurofibromas, less is known about human cNFs. Plexiform neurofibromas are anatomically and histologically distinct from cNFs. Moreover, the ages of onset of the two tumor types are different, as plexiform neurofibromas are congenital.

Increased mast cell density in human cNFs has been reported in comparison to normal skin [22-26]. However, no prior study has examined mast cell subtypes defined by tryptase and chymase expression in human cNFs. To allow efficient development of therapies for $\mathrm{cNFs}$, more information is needed on the cell types and their numbers in cNFs [10] and on the mast cell types present in these tumors [9]. Here, we aim at characterizing mast cells in human cNFs and correlating cNF mast cell content with clinical features.

\section{Materials and Methods}

\section{Patients and Samples}

The study adhered to the principles of the Declaration of Helsinki and was approved by the Ethical Committee of the Hospital District of Southwest Finland (reference number: 131/1803/2017). Research permission was obtained from Turku University Hospital. All participants provided written informed consent.

The participants were patients with NF1 who visited the NF1 clinic operative in Turku University Hospital, Turku, Finland. All patients fulfilled the National Institutes of Health diagnostic criteria for NF1 [27]. The cNFs were excised upon the patient's initiative using $\mathrm{CO}_{2}$ laser. The reasons for removal of the tumors typically included itching, pain, growth, abrasion, and disfigurement. The samples for immunohistochemistry were stored in $10 \%$ neutral formalin immediately after excision and further processed into paraffin blocks. A total of $60 \mathrm{cNF}$ from five females and five males, stored in 32 paraffin blocks, were included in the study. Most samples were excised on a single visit, yet three patients had multiple visits with an interval of $0.2-3.4$ years. In addition, three neurofibromas from a single female patient were processed for mass spectrometry (MS). The tumors for MS analysis were snap-frozen in liquid nitrogen immediately after removal.

For each tumor, clinical characteristics including patient sex, age at sampling, tumor location, tumor growth status, and the patient's total number of cNFs were collected. Tumor location was classified as torso or other than torso. Tumor growth status was estimated by an experienced clinician (S.P.) based on the report given by the patient and classified as likely growing or no evidence of recent growth. The total number of cNFs was classified as $<6$, $6-100,101-500$, or $>500$ based on clinical examination, and further simplified for analysis as $\leq 500$ or $>500$. 


\section{Immunohistochemistry}

The tumors were cut into 3- $\mu \mathrm{m}$ sections. Immunohistochemistry for CD117 was carried out using the Ventana Benchmark Ultra system (Roche, Basel, Switzerland). Polyclonal rabbit antihuman CD117, c-kit antibody (catalog \#A4502; Agilent Dako, Santa Clara, CA, USA) was preceded by antigen retrieval with Cell Conditioning Solution CC1 (950-124; Roche) for $64 \mathrm{~min}$, and the labeling was detected with $3,3^{\prime}$-diaminobenzidine (DAB) as a chromogen (ultraView Universal DAB Detection Kit, 760-500; Roche). To detect chymase, the tissue sections were boiled in 10 mM sodium citrate buffer ( $\mathrm{pH} 6$ ) twice for $5 \mathrm{~min}$ to retrieve the antigens before incubation with 1:100 monoclonal mast cell chymase antibody (CC1) (NB100-693; Novus Biologicals, Cambridge, UK) at $4^{\circ} \mathrm{C}$ overnight and detection using Vectastain Elite ABC-HRP Kit (PK-6102; Vector Laboratories, Burlingame, CA, USA) with $\mathrm{DAB}$ as a chromogen. The protein A-sepharose purified rabbit polyclonal antibody for human skin tryptase (final concentration $0.37 \mu \mathrm{g} / \mathrm{mL}$ ) [28] was detected using Vectastain Elite ABC-HRP Kit (PK-6101; Vector Laboratories) with DAB. All sections were counterstained with hematoxylin. Psoriatic skin and tonsil were used as positive controls for the tryptase and chymase immunolabeling. Treatments with rabbit IgG or dilution buffer only served as negative controls.

\section{Quantification of Mast Cells in cNFs}

The slides were digitized using Pannoramic 250 and Pannoramic Midi FL slide scanners (3DHistech Ltd., Budapest, Hungary). In each of the resulting high-resolution digital images, the tumor area was manually delineated using the QuPath software, version 0.1.2 [29] to separate the neurofibroma tissue from the surrounding dermis and epidermis. Damaged or unevenly labeled border areas, as well as large ruptures and other processing artifacts, were excluded from the delineated tumor area. The area of the tumor was quantified using the QuPath software. The delineated areas were divided into tiles with a maximum size of $1 \mathrm{~mm}$ x $1 \mathrm{~mm}$ to allow further processing. Tiles containing structures with non-specific antibody binding, such as glands and hair follicles embedded in the tumor, were excluded. Positively immunolabeled cells and all nuclei were separately counted with the machine learning-based approach implemented in the Orbit image analysis software, version 3.08 [30]. Either all immunopositive cells or a large number of negative nuclei were marked in a representative $1 \mathrm{~mm}^{2}$ image tile to train the segmentation models for cell detection. Separate models were prepared for tiles with low and high background signal, the latter representing only a minority of all tiles. The resulting models were validated by visually evaluating the results in tiles other than the one used for training. The segmentation models were then used to count all positively immunolabeled cells and all nuclei in all the tiles, yielding wholetumor total counts of immunopositive and all cells. The immunolabelings for CD117, tryptase, and chymase were processed separately.

\section{MS Analysis}

Separate samples were cut from frozen tumor and the overlying skin. The samples were sonicated for $5 \mathrm{~min}$ (five cycles of $30 \mathrm{~s}$ on, $30 \mathrm{~s}$ off) in $50 \mu \mathrm{L}$ of $100-\mathrm{mM}$ triethylammonium bicarbonate buffer containing protease inhibitors (Complete Mini; Roche), followed by pressure-based cell lysis using a Barocycler NEP 2320 instrument (Pressure BioSciences, Easton, MA, USA; 60 cycles of $50 \mathrm{~s}$ at $30^{\circ} \mathrm{C}$ and $\left.310 \mathrm{MPa}\right)$. Sonication was repeated to disrupt DNA. Sodium dodecyl sulfate was added to a final concentration of $5 \%$. The samples were heated for $5 \mathrm{~min}$ at $95^{\circ} \mathrm{C}$ and cooled to room temperature. Non-soluble material was removed by centrifugation at $17,000 \mathrm{~g}$ for $20 \mathrm{~min}$. Protein concentrations were measured using the Lowry method. $50 \mu \mathrm{g}$ protein was digested with trypsin using S-Trap micro spin columns (ProtiFi, Farmingdale, NY, USA) according to the manufacturer's protocol.

The liquid chromatography-electrospray ionization-MS/MS analyses were performed on a nanoflow high-performance liquid chromatography system Easy-nLC 1200 coupled to the Q Exactive HF mass spectrometer (Thermo Fisher Scientific, Bremen, Germany) equipped with a nano-electrospray ionization source. Peptides (600 ng) were separated inline using a 40-cm C18 column (75 $\mu \mathrm{m}$, ReproSil-Pur $1.9 \mu \mathrm{m} 120 \AA$ C18-AQ; Dr. Maisch HPLC $\mathrm{GmbH}$, Germany). The column temperature was $60^{\circ} \mathrm{C}$ and flow rate $300 \mathrm{~nL} / \mathrm{min}$. The mobile phase consisted of water with $0.1 \%$ formic acid (solvent $\mathrm{A}$ ) and acetonitrile/water (80:20, v/v) with $0.1 \%$ formic acid (solvent B). A two-step gradient was used: $90 \mathrm{~min}$ from $5 \%$ to $21 \%$ of eluent B, followed by 30 min from $21 \%$ to $36 \%$ of B. The MS data were acquired automatically using Thermo Xcalibur 4.1 software (Thermo Fisher Scientific). The proteins were quantified with data-independent acquisition (DIA) method. The duty cycle contained one full scan (400-1,000 m/z) and $40 \mathrm{MS} /$ MS scans covering the mass range 400-1,000 with isolation window $15 \mathrm{~m} / \mathrm{z}$.

Data were analyzed using Spectronaut Pulsar software (Biognosys, Schlieren, Switzerland). Pulsar is a search engine, integrated into Spectronaut for spectral library generation. First, a spectral library containing data from all DIA runs was generated with Pulsar. Proteins from individual samples were then identified by comparison against the generated spectral library. Data were normalized before quantification. For protein identification, $p$ values $<0.01$ and quantification $Q$ values $<0.05$ were required.

\section{Statistical Analysis}

The primary outcome was the proportion of immunopositive cells out of all cells, expressed as percentage and denoted below with brackets, e.g., $\left[\mathrm{CD} 117^{+}\right]$. In addition, the immunopositive cell density, i.e., the number of positive cells per area $\left(\right.$ cells $\left./ \mathrm{mm}^{2}\right)$ was calculated. The proportions of $\mathrm{MC}_{\mathrm{TC}}, \mathrm{MC}_{\mathrm{T}}$, and $\mathrm{MC}_{\mathrm{C}}$ subtypes in each tumor were estimated using two approaches:

In order to calculate the minimum proportion of the $\mathrm{MC}_{\mathrm{TC}}$ subtype, the percentage of cells immunoreactive for CD117 out of all cells was used as an estimate of the total abundance of mast cells, i.e., $\left[\mathrm{CD} 117^{+}\right]=\left[\mathrm{MC}_{\mathrm{TC}}\right]+\left[\mathrm{MC}_{\mathrm{T}}\right]+\left[\mathrm{MC}_{\mathrm{C}}\right]$. Tryptase-positive cells may represent either $\mathrm{MC}_{\mathrm{TC}}$ or $\mathrm{MC}_{\mathrm{T}}$ : $\left[\right.$ tryptase $\left.{ }^{+}\right]=\left[\mathrm{MC}_{\mathrm{TC}}\right]+$ $\left[\mathrm{MC}_{\mathrm{T}}\right]$. Analogously for chymase, $\left[\right.$ chymase $\left.^{+}\right]=\left[\mathrm{MC}_{\mathrm{TC}}\right]+\left[\mathrm{MC}_{\mathrm{C}}\right]$. Since $\left[\mathrm{MC}_{\mathrm{T}}\right]=\left[\right.$ tryptase $\left.^{+}\right]-\left[\mathrm{MC}_{\mathrm{TC}}\right]$ and $\left[\mathrm{MC}_{\mathrm{C}}\right]=\left[\right.$ chymase $\left.^{+}\right]-$ $\left[\mathrm{MC}_{\mathrm{TC}}\right]$, we obtain $\left[\mathrm{CD} 117^{+}\right]=\left[\right.$tryptase $\left.^{+}\right]+\left[\right.$chymase $\left.^{+}\right]-\left[\mathrm{MC}_{\mathrm{TC}}\right]$. Consequently, when the sum of the proportions of tryptase- and chymase-positive cells exceeded the CD117-positive cells, the excess was considered positive for both tryptase and chymase, i.e., to represent the $\mathrm{MC}_{\mathrm{TC}}$ subtype: $\left[\mathrm{MC}_{\mathrm{TC}}\right]=\max \left(0\right.$, $\left[\right.$ tryptase $\left.{ }^{+}\right]+[$chymase $\left.\left.{ }^{+}\right]-\left[\mathrm{CD} 117^{+}\right]\right)$. The proportions of the $\mathrm{MC}_{\mathrm{T}}$ and $\mathrm{MC}_{\mathrm{C}}$ subtypes could then be obtained as $\left[\mathrm{MC}_{\mathrm{T}}\right]=\left[\right.$ tryptase $\left.{ }^{+}\right]-\left[\mathrm{MC}_{\mathrm{TC}}\right]$ and $\left[\mathrm{MC}_{\mathrm{C}}\right]=\left[\right.$ chymase $\left.^{+}\right]-\left[\mathrm{MC}_{\mathrm{TC}}\right]$

The maximum proportion of the $\mathrm{MC}_{\mathrm{TC}}$ subtype was the smaller of the tryptase- and chymase-immunopositive cell proportions, $\left[\mathrm{MC}_{\mathrm{TC}}\right]=\min \left(\left[\right.\right.$ tryptase $\left.^{+}\right],\left[\right.$chymase $\left.\left.^{+}\right]\right)$, i.e., the size of the largest 
possible intersection between cells positive for the two proteinases. The proportions of the $\mathrm{MC}_{\mathrm{T}}$ and $\mathrm{MC}_{\mathrm{C}}$ subtypes were obtained as $\left[\mathrm{MC}_{\mathrm{T}}\right]=\left[\right.$ tryptase $\left.^{+}\right]-\left[\mathrm{MC}_{\mathrm{TC}}\right]$ and $\left[\mathrm{MC}_{\mathrm{C}}\right]=\left[\right.$ chymase $\left.^{+}\right]-\left[\mathrm{MC}_{\mathrm{TC}}\right]$.

Since it has been suggested that the cells immunopositive for chymase only are actually apoptotic $\mathrm{MC}_{\mathrm{TC}}$ where tryptase-heparin proteoglycan complexes have diffused away due to their smaller size while larger chymase-heparin proteoglycan complexes are still retained $[11,20]$, an analysis assuming that all chymase-positive cells represent $\mathrm{MC}_{\mathrm{TC}}$ was conducted as a sensitivity analysis. Here, $\left[\mathrm{MC}_{\mathrm{TC}}\right]=\left[\right.$ chymase $\left.^{+}\right]$and $\left[\mathrm{MC}_{\mathrm{T}}\right]=\max \left(0,\left[\right.\right.$ tryptase $\left.\left.^{+}\right]-\left[\mathrm{MC}_{\mathrm{TC}}\right]\right)$.

Coefficient of variation $(\mathrm{CV})$, defined as the ratio of standard deviation and mean, was used to estimate the degree of variation within tumors, patient-wise between tumors, and between patients. The within-tumor variation was computed between the 1 $\mathrm{mm}^{2}$ tiles of each tumor. The between-tumor variation was calculated between the tumors of each patient after summing the data from different tiles. For the between-patient variation, data from the different tumors of each patient were averaged. Linear mixed effects regression with a random intercept for each patient was used for statistical comparisons between the within-tumor and between-tumor CVs, and Wilcoxon signed rank test was used to compare between-tumor and between-patient CVs. Moreover, analysis of variance (ANOVA) was used to test for differences between patients.

The abundances of tryptase- and chymase-immunopositive cells were compared using a paired Wilcoxon signed rank test. The proportions of positive cells were analyzed with respect to histologically determined and clinical characteristics. The histologically determined characteristics considered were tumor size and cellularity. The tumor size was estimated as the average of the delineated tumor areas of the CD117-, tryptase-, and chymase-labeled sections. While the size of a fixed tissue section does not equal the clinical appearance of the tumor, it reflects the original tumor size. Cellularity in each section was calculated as the ratio of the number of all cells and tumor area, and the mean of the three sections was used to represent the whole tumor.

Continuous variables were dichotomized relative to their median. For statistical analysis, the percentages of positive cells were square-root transformed to ensure normality of residuals. Linear mixed effects regression with a random intercept for each patient was used for the analysis to allow for within-patient correlation. All statistical analyses were conducted with the R software, version 3.3.2 (www.r-project.org) and package lmerTest, version 2.0-33.

\section{Results}

Sixty human cNFs from ten individuals with NF1 were studied, with 3-15 samples per patient (Table 1). The immunolabeling for CD117 was carried out in 60 tumors, while results for tryptase and chymase were available for 59 cNFs. All samples showed cells positive for the antigens studied (Fig. 1). The median proportion of CD117positive cells out of all cells observed in the tissue sections was $5.5 \%$ (range $0.06-14.4 \%$ ) (Table 2). Cells showing immunoreaction for chymase were more abundant than cells positive for tryptase, as the median proportion of
Table 1. Clinical characteristics of the patients and the cutaneous neurofibromas studied histologically

$N$

$n /$ patient, median (range)

60

Sex, $n(\%)$

Female

Male

4 (3 to 15$)$

Age, years, median (range)

Number of patients' cutaneous neurofibromas, $n(\%)$

$6-100$

$101-500$

$30(50.0 \%)$

$30(50.0 \%)$

$33(24$ to 52$)$

$>500$

$8(13.3 \%)$

$26(43.3 \%)$

$25(41.7 \%)$

Not available

$1(1.7 \%)$

Body location of the tumors studied, $n(\%)$

Torso

Upper extremity

$50(83.3 \%)$

$3(5.0 \%)$

$1(1.7 \%)$

Lower extremity

$2(3.3 \%)$

Other

$4(6.7 \%)$

Growth status of the tumors studied, $n$ (\%)

Growing

$36(60.0 \%)$

No evidence of recent growth

$24(40.0 \%)$

chymase-positive cells was 5.0\% (range 1.1-15.9\%), and tryptase-positive cells $4.0 \%$ (range $1.2-7.0 \%)(p<0.001$ ). The median densities of cells immunopositive for CD117, tryptase, and chymase were 280,243 , and 250 cells $/ \mathrm{mm}^{2}$, respectively (Table 2 ). Immunopositive cells were evenly scattered in the tumors and no mast cell clusters were detected.

The proportions of the different mast cell subtypes were estimated using the results from CD117, tryptase, and chymase immunolabelings. The $\mathrm{MC}_{\mathrm{TC}}$ was the most common mast cell subtype, representing a median proportion of $55.9-85.5 \%$ of mast cells in cNFs (Table 2 ). The median proportions of $\mathrm{MC}_{\mathrm{T}}$ and $\mathrm{MC}_{\mathrm{C}}$ were $0.0-12.6 \%$ and $9.0-24.4 \%$, respectively. If all chymase-positive cells represented $\mathrm{MC}_{\mathrm{TC}}[11,20]$, a median of $100.0 \%$ (range $43.0-100.0 \%$ ) of mast cells would be $\mathrm{MC}_{\mathrm{TC}}$ and, consequently, $0.0 \%$ (range $0.0-57.0 \%$ ) of mast cells would be $\mathrm{MC}_{\mathrm{T}}$.

\section{Association of cNF Mast Cell Content with Clinical Characteristics}

The variation between tumors from the same individual was similar as within tumors with respect to the proportion of cells immunopositive for CD117, tryptase, and chymase $(p=0.68, p=0.11$, and $p=0.10$, respectively; Table 2). A major determinant of mast cell percentage was the tumor size: for example, the median proportion of cells immunopositive for CD117 was $6.6 \%$ 


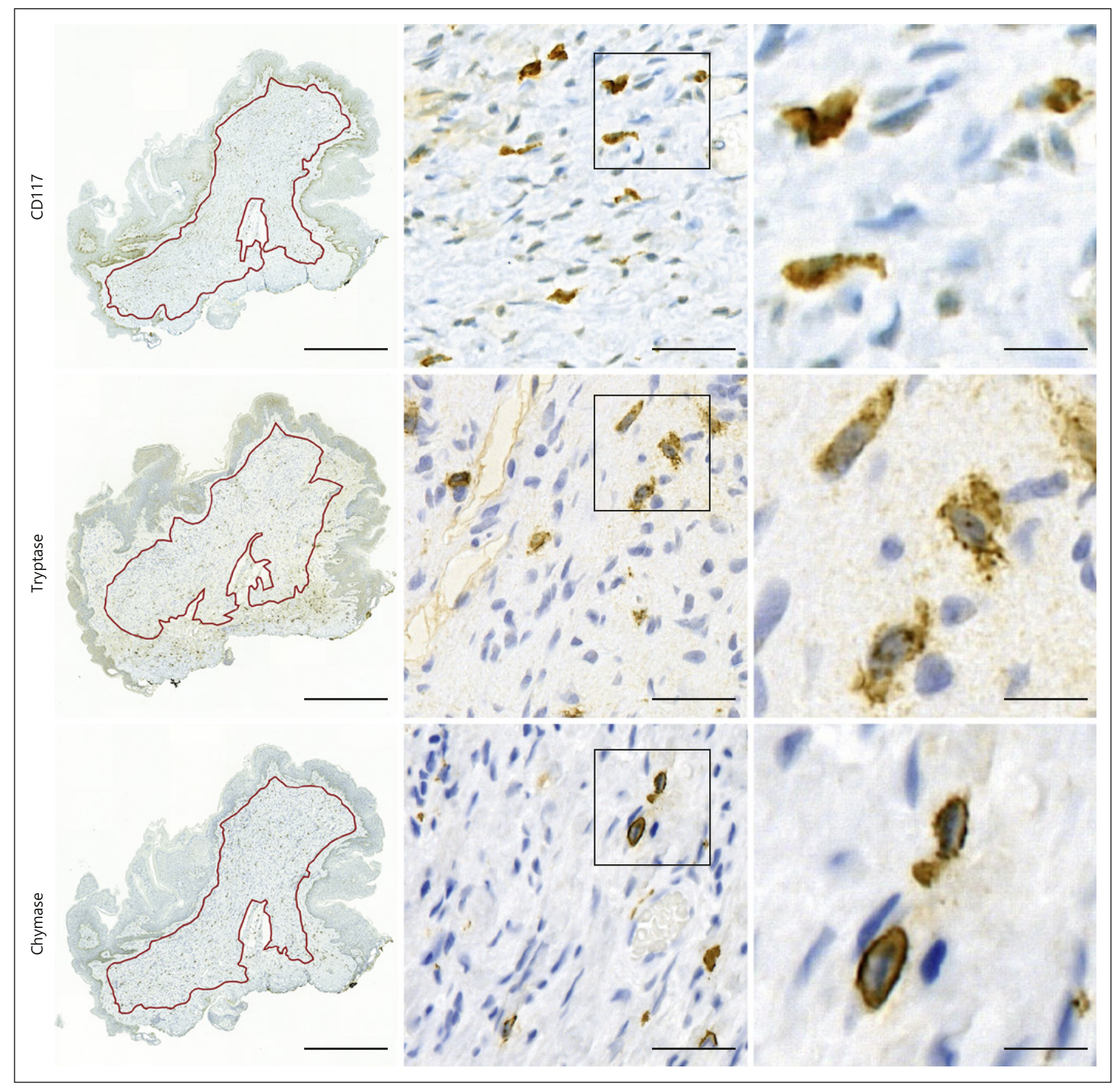

Fig. 1. Representative examples of immunohistochemical detection of the mast cell markers CD117, tryptase, and chymase in human cutaneous neurofibromas. The left column also shows delin- eated neurofibroma area, with the red line separating the tumor tissue from the surrounding skin. Scale bar, $500 \mu \mathrm{m}$ in the left column, $25 \mu \mathrm{m}$ in the middle column, and $10 \mu \mathrm{m}$ in the right column. (range 3.3-14.4\%) in tumors below the median size of 5.2 $\mathrm{mm}^{2}$, while larger tumors had a median of $3.3 \%$ (range 0.06-13.8\%) of CD117-positive cells ( $p=0.057$; Fig. 2 ). A similar association with tumor size was observed for tryptase- $(p=0.016)$ and chymase- $(p<0.001)$ positive cells. Nevertheless, the absolute number of immunopositive cells was higher in larger tumors. The cellularity of the tumors, i.e., the total number of cells per tumor area, was not associated with the proportion of immunopositive cells (Fig. 2). 
Table 2. Abundance of mast cells in human cutaneous neurofibromas

\begin{tabular}{|c|c|c|}
\hline & Median & Range \\
\hline \multicolumn{3}{|l|}{ CD117-immunopositive cells } \\
\hline Proportion of all cells, \% & 5.5 & 0.1 to 14.4 \\
\hline Density, cells $/ \mathrm{mm}^{2}$ & 280 & 2 to 932 \\
\hline Number of mast cells counted & 1,076 & 68 to 21,673 \\
\hline \multicolumn{3}{|l|}{$\mathrm{CV}$ of proportion } \\
\hline Within tumor & 0.4 & 0.0 to 1.9 \\
\hline Within individual & 0.4 & 0.2 to 0.8 \\
\hline Between individuals & 0.5 & \\
\hline \multicolumn{3}{|l|}{ Tryptase-immunopositive cells } \\
\hline Proportion of all cells, \% & 4.0 & 1.2 to 7.0 \\
\hline Density, cells $/ \mathrm{mm}^{2}$ & 243 & 54 to 672 \\
\hline Number of mast cells counted & 1,262 & 56 to 14,837 \\
\hline \multicolumn{3}{|l|}{$\mathrm{CV}$ of proportion } \\
\hline Within tumor & 0.4 & 0.0 to 1.3 \\
\hline Within individual & 0.4 & 0.2 to 0.6 \\
\hline Between individuals & 0.3 & \\
\hline \multicolumn{3}{|l|}{ Chymase-immunopositive cells } \\
\hline Proportion of all cells, \% & 5.0 & 1.1 to 15.9 \\
\hline Density, cells $/ \mathrm{mm}^{2}$ & 250 & 54 to 883 \\
\hline Number of mast cells counted & 1,066 & 183 to 10,435 \\
\hline \multicolumn{3}{|l|}{$\mathrm{CV}$ of proportion } \\
\hline Within tumor & 0.5 & 0.1 to 2.2 \\
\hline Within individual & 0.4 & 0.2 to 0.7 \\
\hline Between individuals & 0.5 & \\
\hline \multicolumn{3}{|l|}{ Minimum proportion of $\mathrm{MC}_{\mathrm{TC}}, \%$} \\
\hline $\mathrm{MC}_{\mathrm{TC}} /$ mast cells & 55.9 & 0.0 to 93.7 \\
\hline $\mathrm{MC}_{\mathrm{T}} /$ mast cells & 12.6 & 0.0 to 100.0 \\
\hline $\mathrm{MC}_{\mathrm{C}} /$ mast cells & 24.4 & 0.0 to 100.0 \\
\hline $\mathrm{MC}_{\mathrm{TC}} /$ all cells & 2.4 & 0.0 to 6.3 \\
\hline $\mathrm{MC}_{\mathrm{T}} /$ all cells & 0.5 & 0.0 to 4.8 \\
\hline $\mathrm{MC}_{\mathrm{C}} /$ all cells & 1.4 & 0.0 to 9.1 \\
\hline \multicolumn{3}{|l|}{ Maximum proportion of $\mathrm{MC}_{\mathrm{TC}}, \%$} \\
\hline $\mathrm{MC}_{\mathrm{TC}} /$ mast cells & 85.5 & 21.0 to 98.0 \\
\hline $\mathrm{MC}_{\mathrm{T}} /$ mast cells & 0.0 & 0.0 to 57.0 \\
\hline $\mathrm{MC}_{\mathrm{C}} /$ mast cells & 9.0 & 0.0 to 79.0 \\
\hline $\mathrm{MC}_{\mathrm{TC}} /$ all cells & 3.7 & 1.1 to 7.0 \\
\hline $\mathrm{MC}_{\mathrm{T}} /$ all cells & 0.0 & 0.0 to 3.7 \\
\hline $\mathrm{MC}_{\mathrm{C}} /$ all cells & 0.4 & 0.0 to 12.5 \\
\hline
\end{tabular}

The median and range are shown for values from the total of 60 tumors studied. The mast cell subtypes have been calculated under two conditions, assuming that the proportion of the subtype expressing both tryptase and chymase $\left(\mathrm{MC}_{\mathrm{TC}}\right)$ is either as small or as large as possible (see Methods for details). CV, coefficient of variation; $\mathrm{MC}_{\mathrm{TC}}$, mast cells expressing both tryptase and chymase; $\mathrm{MC}_{\mathrm{T}}$, mast cells expressing tryptase only; $\mathrm{MC}_{\mathrm{C}}$, mast cells expressing chymase only.

Analysis of variance indicated significant differences between patients in the proportion of cells immunoreactive for $\operatorname{CD} 117\left(F_{9,50}=9.201, p=4.7 \times 10^{-8}\right)$, tryptase $\left(F_{9,49}=3.768, p=0.001\right)$, and chymase $\left(F_{9,49}=9.017, p=\right.$
$7.1 \times 10^{-8}$ ), yet the variation between patients did not differ from the within-patient variation between tumors (CD117: $p=0.32$; tryptase: $p=0.08$; chymase: $p=0.11$; Table 2). Tumors from individuals younger than the median age of 33 years had a significantly higher proportion of cells immunopositive for the studied mast cell markers than cNFs from older individuals (Fig. 3). Moreover, putatively growing tumors had more positive cells than tumors with no recent growth. The densities of CD117-, tryptase-, and chymase-positive cells in cNFs did not differ by sex or the patient's total number of cNFs (Fig. 3). The cNFs excised from the torso showed slightly higher proportions of cells positive for tryptase (median $4.4 \%$, range $1.6-7.0 \%$ ) and chymase (median $5.8 \%$, range $1.3-$ $15.9 \%)$ than tumors from other locations (tryptase: median $2.9 \%$, range $1.3-5.5 \%$; chymase: median 3.2\%, range 1.4-5.1\%). However, the differences were not statistically significant and only a few tumors from areas other than torso were included (Fig. 3).

\section{Comparison of Tryptase and Chymase Protein Levels between $c N F$ and Skin}

In order to assess the relative abundance of chymase and tryptase proteins in cNFs compared to skin, three cNFs and the overlying skin were analyzed using MS. A total of 2,800 proteins were identified, $98.6 \%$ of which were found in both cNF and skin. Both tryptase and chymase were quantified based on three unique peptides, yielding a sequence coverage of 38-49\% for tryptase and $58 \%$ for chymase. The abundance of tryptase was 2.76 fold higher in cNFs compared to the adjacent skin, while the abundance of chymase was 3.80-fold higher in cNFs compared to skin.

\section{Discussion}

The present dataset is a comprehensive characterization of mast cells in cNFs and their associations with histological and clinical features. In addition, the data are the first to describe mast cell subtypes based on tryptase and chymase expression in human cNFs. In concordance with previous reports [22-24, 26], mast cells were abundant in cNFs. Specifically, the median proportions of cells expressing CD117, tryptase, and chymase ranged from 4.0 to $5.5 \%$ in cNFs and the highest observed proportion of cells immunopositive for chymase was as high as $16 \%$. The median densities of cells immunoreactive for CD117, tryptase, and chymase were 280, 243, and 250 cells $/ \mathrm{mm}^{2}$, respectively. The mast cell densities reported 


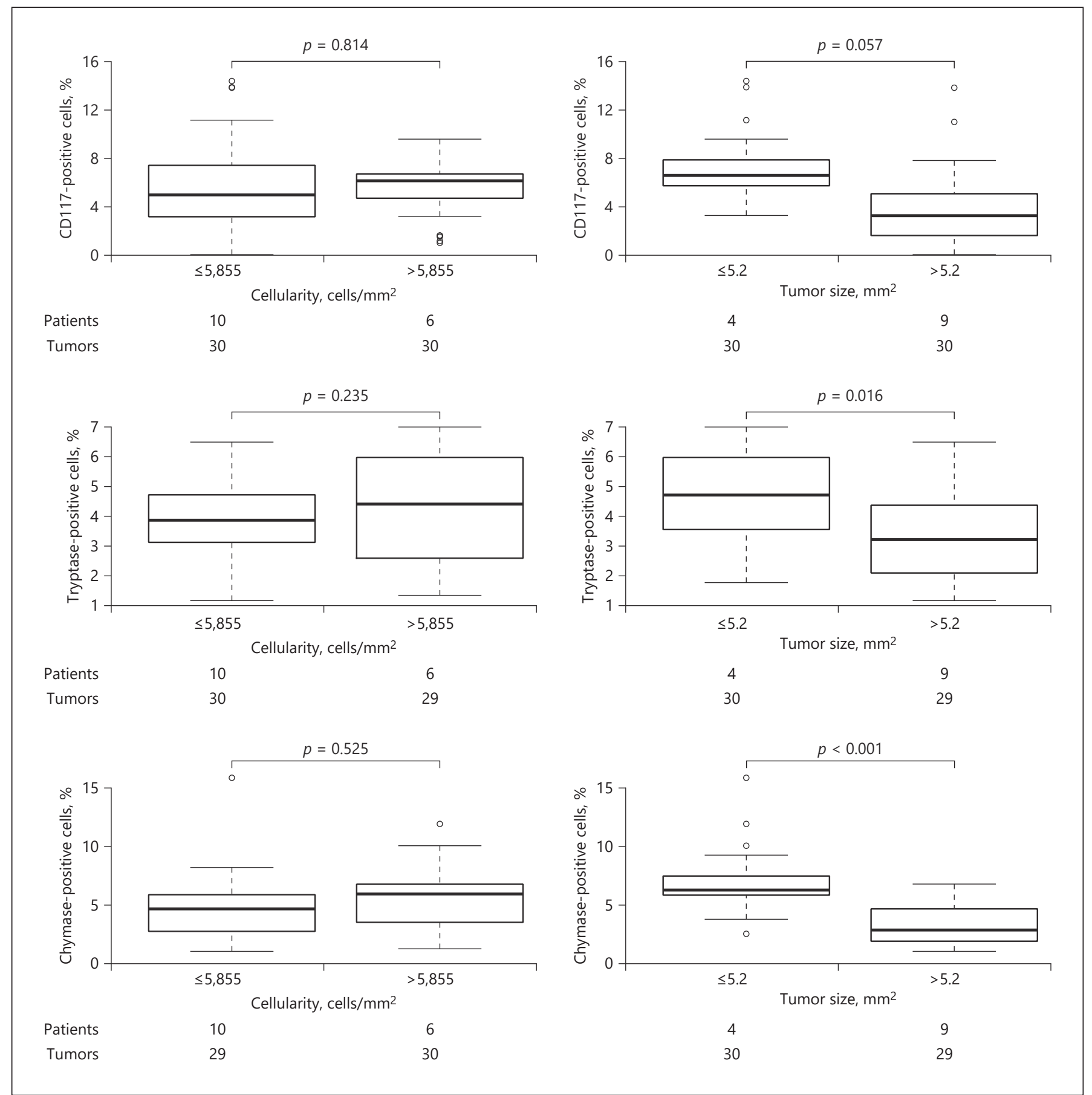

Fig. 2. Association of tumor cellularity and tumor size with the proportion of cells immunopositive for CD117, tryptase, and chymase in human cutaneous neurofibromas (cNFs). The $p$ values have been

computed using linear mixed effects regression with a random intercept for each individual. The numbers of tumor samples and patients with NF1 in each category are shown below the panels.

in skin typically range between 20 and 150 cells $/ \mathrm{mm}^{2}$ [11, $20,31]$. The high number of mast cells in cNFs compared to unaffected skin is also supported by our small-scale MS analysis showing 2.8-3.8-fold increase in the amounts

of tryptase and chymase proteins in cNFs compared to the overlying skin. Changes in mast cell density compared to healthy skin have also been reported in other skin conditions, such as melanoma, xanthoma, and in- 

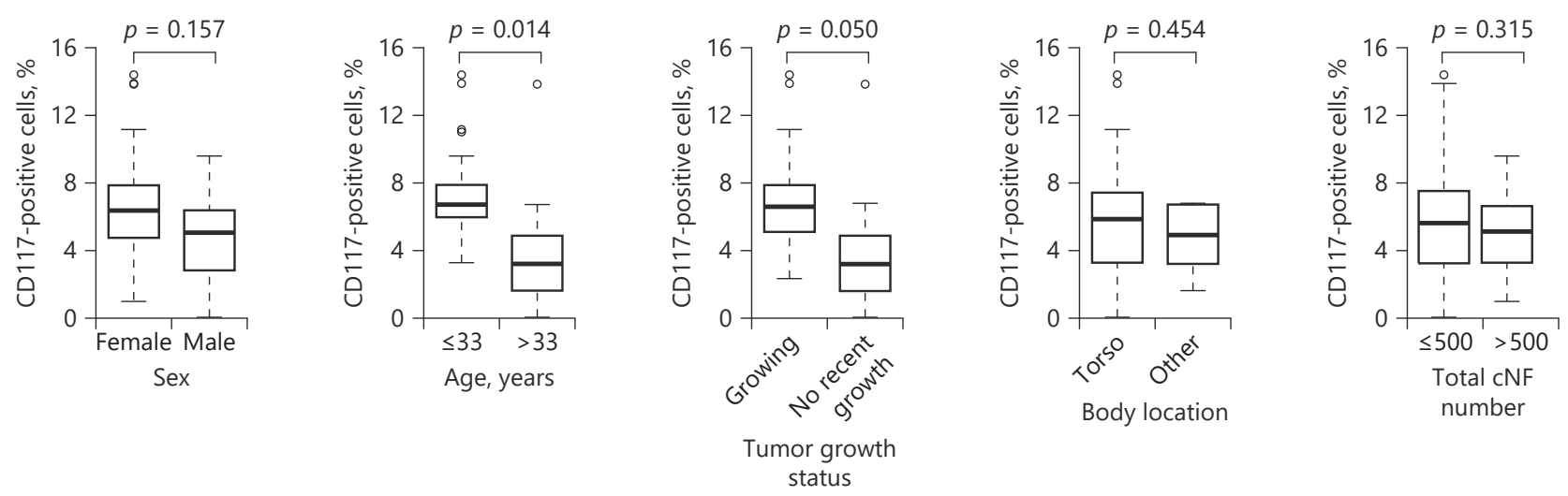

Patients $\quad 5 \quad 5$
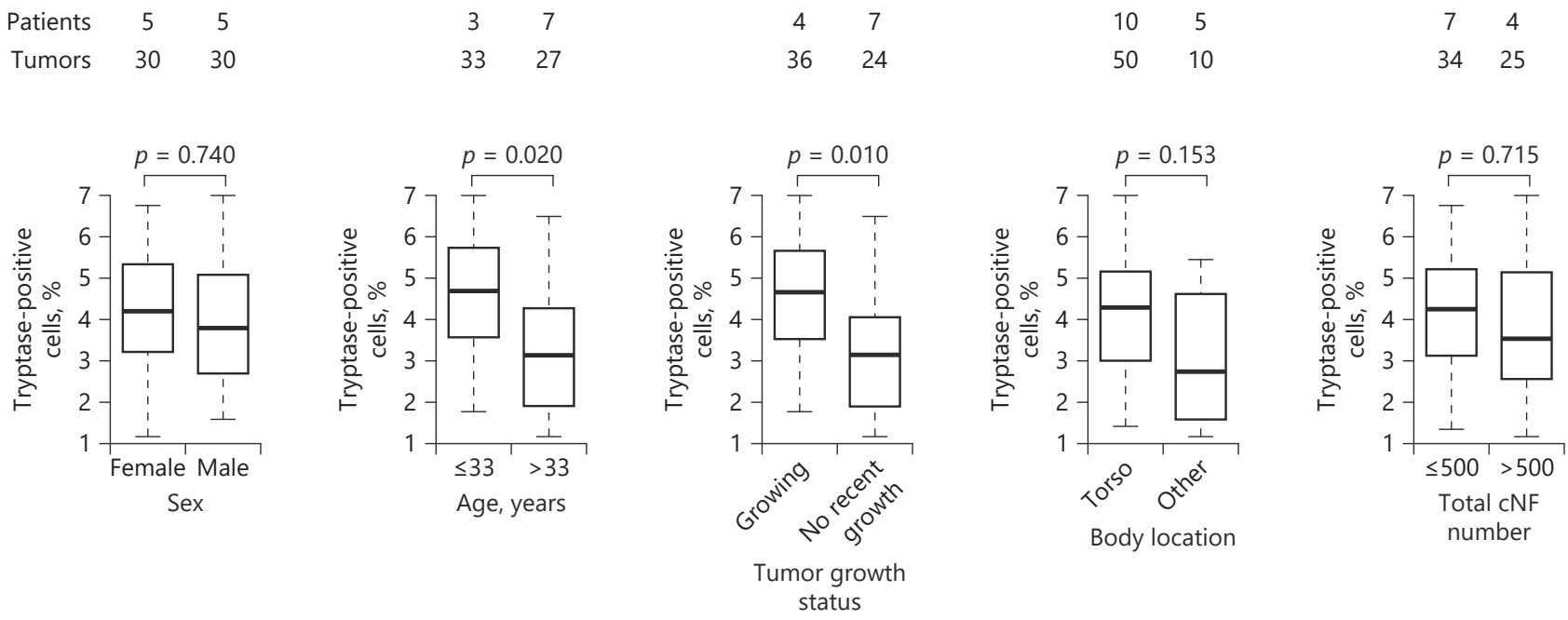

Patients $5 \quad 5$

Tumors $\quad 30 \quad 29$
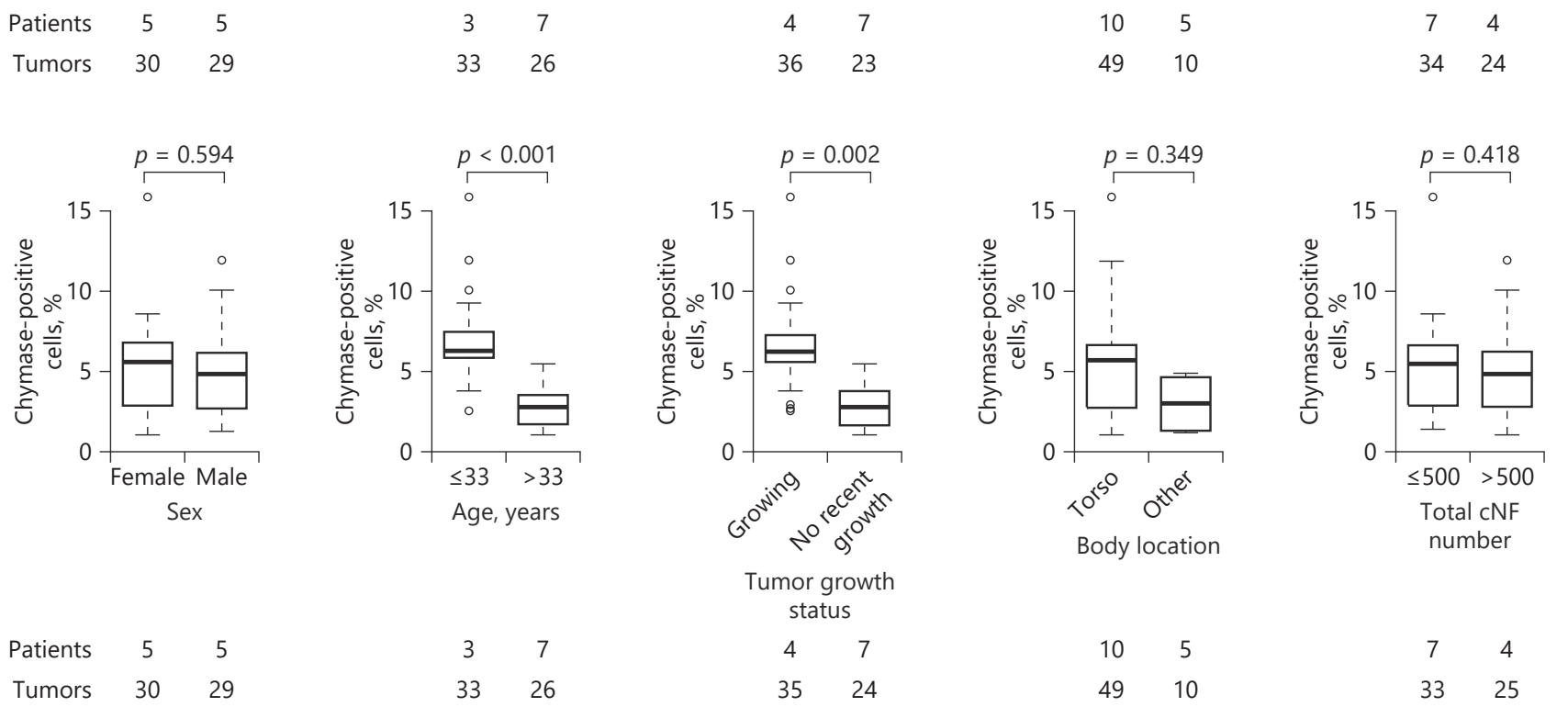

Fig. 3. Association of clinical features with the proportion of cells immunopositive for CD117, tryptase, and chymase in human cutaneous neurofibromas (cNFs). The $p$ values have been computed

using linear mixed effects regression with a random intercept for each individual. The numbers of tumor samples and patients with NF1 in each category are shown below the panels. 
flammatory diseases $[11,13,32,33]$. For example, upper dermis of psoriatic skin contains 257-308 mast cells/ $\mathrm{mm}^{2}[11]$.

The $\mathrm{MC}_{\mathrm{TC}}$ constituted the majority (56-86\%) of mast cells in cNFs. Interestingly, chymase-positive cells were more abundant than cells positive for tryptase. Consequently, the $\mathrm{MC}_{\mathrm{C}}$ type represented a median of $9-24 \%$ of mast cells. This is in striking contrast to normal skin, where virtually all mast cells are $\mathrm{MC}_{\mathrm{TC}}[15-17,31]$. Also the MS data suggest that chymase expression is increased even more than tryptase expression in cNFs compared to normal skin. Previously, increased number of mast cells expressing enzymatically active chymase has been reported in radiotherapy-induced skin fibrosis [34]. Chymase is known to be involved in matrix remodeling, including activation of procollagenase, degradation of fibronectin, and activation of latent transforming growth factor beta (TGF $\beta$ ) that drives collagen synthesis by fibroblasts [11]. It can be speculated that the increased chymase expression in cNFs contributes to the accumulation of collagens in cNFs.

Our results showed marked differences in mast cell content between tumors both within and between individuals. In some cNFs, approximately every seventh cell was mast cell, while some tumors showed very low percentage of mast cells ( 1\%). As reported previously [26], sex of a patient was not associated with the abundance of mast cells in cNFs. Instead, small tumors, tumors estimated to be growing, and tumors from patients $\leq 33$ years of age were observed to harbor higher proportions of mast cells. These observations may be interrelated since younger patients are more likely to have small and yet growing tumors.

The concept of high abundance of mast cells in growing tumors is supported by the clinical observations that growing cNFs are often itchy (personal note of S. Peltonen) and that the pruritic skin of individuals with NF1 may contain emerging, clinically undetectable microneurofibromas $[35,36]$. The very early neurofibromas are associated with focal sprouting of sensory endings of non-peptidergic C-fibers [36]. These unmyelinated nerve fibers mediate chronic pruritus and may be responsive to mediators secreted by mast cells. However, the association between cNF mast cell content and pruritus remains to be addressed by future studies. Mast cell infiltration has previously been reported in developing cNFs $[35,36]$, and the current results further support the idea that mast cells are present in the early phases of $\mathrm{cNF}$ development. It is noteworthy that although mast cells represented a higher proportion of all cells in small ver-

Mast Cells in Human Cutaneous Neurofibromas sus large $\mathrm{CNF}$, the absolute numbers of mast cells were higher in large tumors. This suggests that the number of mast cells in cNFs increases along with tumor growth. Mechanistically, loss of Nf1 in Schwann cells is known to increase the production of SCF in murine models of plexiform neurofibroma [37]. Nf1 haploinsufficient mast cells are more sensitive to SCF than cells with intact $N f 1$ $[37,38]$. The SCF derived from Schwann cells is a key effector for the recruitment of mast cells into plexiform neurofibromas [39]. Nf1 deficiency enhances the production of TGF $\beta$ by mast cells, which drives fibroblasts to increased collagen deposition, migration, and remodeling of extracellular matrix [40].

The abundance of mast cells in human cNFs was assessed using closely supervised automated cell counting. The reliability of the results was verified by manual training and validation of the detection models. The automated counting procedure allowed us to determine the total numbers of both immunopositive and all cells in the tissue sections consistently over all samples and thus provided a valid basis for comparisons between tumors. The resulting cell densities may show some differences compared to studies where positive cells have been counted manually. Another source of variation between studies is the thickness of tissue sections, as the present samples were cut to $3-\mu \mathrm{m}$ sections while many previous studies have used $5-\mu \mathrm{m}$ sections. The thinner sections may lead to lower apparent cell density and therefore cause underestimation of mast cells in cNFs compared to previous reports on normal skin. Naturally, estimates based on the analysis of two-dimensional tissue sections differ from the actual number of cells per cubic millimeter in the three-dimensional tissue. Some previous studies of the different mast cell types have used sequential tryptase and chymase immunolabeling to detect these proteins in each cell $[17,18,31]$. Such an approach was not optimal for counting all mast cells in a large set of tumors, and we therefore based our conclusions regarding mast cell types on frequencies of tryptase- and chymase-positive cells immunolabeled in different tissue sections. Finally, the cNFs were excised upon the patient's initiative and the material may therefore show bias towards itchy or painful tumors.

If mast cells are related to cNF growth, either as a cause or a consequence, the results provide support for targeting mast cells to prevent tumor growth, predominantly in small, early-stage cNFs. Mast cells are the target of many developmental and approved drugs. In addition to the mast cell stabilizer ketotifen and CD117 inhibitor imatinib that have already been tested in the context of NF1, 
accumulating information on mast cell subtypes in cNFs may suggest novel therapeutic approaches. Several investigational compounds are under development to target, e.g., chymase and other mast cell proteinases, CD117 and its downstream signaling, and ion channels regulating mast cell activation and degranulation [41]. Together with the previous mechanistic evidence from animal models, the abundance of mast cells in human cNFs and the altered distribution of mast cell types compared to unaffected skin highlight mast cells as a potential therapeutic target in cNFs.

\section{Key Message}

Mast cells are abundant in human cutaneous neurofibromas and their subtypes differ from unaffected skin.

\section{Acknowledgements}

Mass spectrometry analyses were performed at the Turku Proteomics Facility supported by Biocenter Finland. This work is generated within the European Reference Network on Genetic Tumour Risk Syndromes (ERN GENTURIS) - Project ID No. 739547. ERN GENTURIS is partly co-funded by the European Union within the framework of the Third Health Programme "ERN-2016 Framework Partnership Agreement 2017-2021". We thank Ms. Sinikka Collanus and Ms. Anne Koivisto for technical assistance. Mr. Miso Immonen and Ms. Mari Hellén are acknowledged for their help in sample collection.

\section{Statement of Ethics}

The study adhered to the principles of the Declaration of Helsinki and was approved by the Ethical Committee of the Hospital District of Southwest Finland (reference number: 131/1803/2017). Research permission was obtained from Turku University Hospital. All participants provided written informed consent.

\section{Conflict of Interest Statement}

The authors have no conflicts of interest to declare.

\section{Funding Sources}

This publication was supported by a Subagreement from the Johns Hopkins University via the Neurofibromatosis Therapeutic Acceleration Program (NTAP) with funds provided by Grant Agreement form the Bloomberg Family Foundation. Its contents are solely the responsibility of the authors and do not necessarily represent the official views of the Bloomberg Family Foundation or the Johns Hopkins University.

\section{Author Contributions}

R.A.K., E.M., J.P., and S.P. collected the tissue samples. R.A.K., K.A., and E.F. performed the image analysis. P.H. and A.R. performed the mass spectrometry analysis, and R.A.K., E.M., P.H., and A.R. analyzed the results. R.A.K. performed the statistical analyses and drafted the manuscript. All authors participated in study design and interpretation of the results, critically revised the manuscript, and read and approved the final version.

\section{References}

1 Kodra Y, Giustini S, Divona L, Porciello R, Calvieri S, Wolkenstein P, et al. Health-related quality of life in patients with neurofibromatosis type 1: A survey of 129 Italian patients. Dermatology. 2009 Feb;218(3):21520.

2 Jouhilahti EM, Peltonen S, Heape AM, Peltonen J. The pathoetiology of neurofibromatosis 1. Am J Pathol. 2011 May;178(5):19329.

3 Uusitalo E, Rantanen M, Kallionpää RA, Pöyhönen M, Leppävirta J, Ylä-Outinen $\mathrm{H}$, et al. Distinctive Cancer Associations in Patients With Neurofibromatosis Type 1. J Clin Oncol. 2016 Jun;34(17):1978-86.

4 Wallace MR, Marchuk DA, Andersen LB, Letcher R, Odeh HM, Saulino AM, et al. Type 1 neurofibromatosis gene: Identification of a large transcript disrupted in three NF1 patients. Science. 1990;249(4965):181-6.
5 Kallionpää RA, Uusitalo E, Leppävirta J, Pöyhönen M, Peltonen S, Peltonen J. Prevalence of neurofibromatosis type 1 in the Finnish population. Genet Med. 2018;20(9):1082-6.

6 Maertens O, Brems H, Vandesompele J, De Raedt T, Heyns I, Rosenbaum T, et al. Comprehensive NF1 screening on cultured Schwann cells from neurofibromas. Hum Mutat. 2006 Oct;27(10):1030-40.

7 Peltonen J, Jaakkola S, Lebwohl M, Renvall S, Risteli L, Virtanen I, et al. Cellular differentiation and expression of matrix genes in type 1 neurofibromatosis. Lab Invest. 1988 Dec; 59(6):760-71.

8 Olsson Y. Mast Cells In Human Peripheral Nerve. Acta Neurol Scand. 1971;47(3):357-68.

9 Riccardi VM. Current Utilization of Mast Cell Stabilizers for Preemptive Treatment of NF1 Neurofibromas. Neuro Open Journal. 2015 Sep;2(2):67-73
10 Brosseau JP, Pichard DC, Legius EH, Wolkenstein P, Lavker RM, Blakeley JO, et al. The biology of cutaneous neurofibromas: Consensus recommendations for setting research priorities. Neurology. 2018 Jul;91(2):S14-20.

11 Harvima IT, Nilsson G, Suttle MM, Naukkarinen $\mathrm{A}$. Is there a role for mast cells in psoriasis? Arch Dermatol Res. 2008 Oct;300(9): 461-78.

12 Krystel-Whittemore M, Dileepan KN, Wood JG. Mast cell: A multi-functional master cell. Front Immunol. 2016;6:620.

13 Gupta K, Harvima IT. Mast cell-neural interactions contribute to pain and itch. Immunol Rev. 2018 Mar;282(1):168-87.

14 Varricchi G, Galdiero MR, Loffredo S, Marone G, Iannone R, Marone G, et al. Are mast cells MASTers in cancer? Front Immunol. 2017 Apr;8:424. 
15 Irani AA, Schechter NM, Craig SS, DeBlois G, Schwartz LB. Two types of human mast cells that have distinct neutral protease compositions. Proc Natl Acad Sci U S A. 1986;83(12): 4464-8.

16 Weidner N, Austen KF. Heterogeneity of Mast Cells at Multiple Body Sites: Fluorescent Determination of Avidin Binding and Immunofluorescent Determination of Chymase, Tryptase, and Carboxypeptidase Content. Pathol Res Pract. 1993;189(2):156-62.

17 Irani AMA, Bradford TR, Kepley CL, Schechter NM, Schwartz LB. Detection of MC(T) and $\mathrm{MC}(\mathrm{TC})$ types of human mast cells by immunohistochemistry using new monoclonal anti-tryptase and anti-chymase antibodies. J Histochem Cytochem. 1989;37(10): 1509-15.

18 Kankkunen JP, Harvima IT, Naukkarinen A. Quantitative analysis of tryptase and chymase containing mast cells in benign and malignant breast lesions. Int J Cancer. 1997;72(3):385-8.

19 Ibaraki T, Muramatsu M, Takai S, Jin D, Maruyama H, Orino T, et al. The relationship of tryptase- and chymase-positive mast cells to angiogenesis in stage I non-small cell lung cancer. Eur J Cardiothorac Surg. 2005 Oct; 28(4):617-21.

20 Kivinen PK, Nilsson G, Naukkarinen A, Harvima IT. Mast cell survival and apoptosis in organ-cultured human skin. Exp Dermatol. 2003 Feb;12(1):53-60.

21 Yang FC, Ingram DA, Chen S, Zhu Y, Yuan J, Li X, et al. Nf1-dependent tumors require a microenvironment containing Nf1+/-- and ckit-dependent bone marrow. Cell. 2008 Oct; 135(3):437-48.

22 Kamide R, Nomura N, Niimura M. Characterization of mast cells residing in cutaneous neurofibromas. Dermatologica. 1989; 179 Suppl 1:124.

23 Nürnberger M, Moll I. Semiquantitative aspects of mast cells in normal skin and in neurofibromas of neurofibromatosis types 1 and 5. Dermatology. 1994;188(4):296-9.
24 Friedrich RE, Naber U, Glatzel M, Hagel C. Vessel and mast cell densities in sporadic and syndrome-associated peripheral nerve sheath tumors. Anticancer Res. 2015 Sep;35(9): 4713-22.

25 Trentin Brum S, Demasi AP, Fantelli Stelini R, Cintra ML, Cavalcanti De Araujo V, Borges Soares A. Endoglin is Highly Expressed in Human Mast Cells. Appl Immunohistochem Mol Morphol. 2019 Sep;27(8):613-7.

26 Jia J, Zhang H, Zhang H, Liu W, Du H, Shu $\mathrm{M}$, et al. AR facilitates YAP-TEAD interaction with the AM promoter to enhance mast cell infiltration into cutaneous neurofibroma. Sci Rep. 2019 Dec;9(1):19346.

27 National Institutes of Health Consensus Development Conference. Neurofibromatosis. Conference statement. Arch Neurol. 1988 May;45(5):575-8.

28 Harvima IT, Naukkarinen A, Harvima RJ, Fräki JE. Immunoperoxidase and enzymehistochemical demonstration of human skin tryptase in cutaneous mast cells in normal and mastocytoma skin. Arch Dermatol Res. 1988 Aug;280(6):363-70.

29 Bankhead P, Loughrey MB, Fernández JA, Dombrowski Y, McArt DG, Dunne PD, et al. QuPath: Open source software for digital pathology image analysis. Sci Rep. 2017 Dec; $7(1): 16878$

30 Stritt M, Stalder AK, Vezzali E. Orbit image analysis: An open-source whole slide image analysis tool. PLoS Comput Biol. 2020;16(2): e1007313.

31 Hermes B, Feldmann-Böddeker I, Welker P, Algermissen B, Steckelings MU, Grabbe J, et al. Altered expression of mast cell chymase and tryptase and of c-Kit in human cutaneous scar tissue. J Invest Dermatol. 2000;114(1): 51-5.

32 Siiskonen H, Poukka M, Bykachev A, TyyneläKorhonen K, Sironen R, Pasonen-Seppänen $S$, et al. Low numbers of tryptase+ and chymase+ mast cells associated with reduced survival and advanced tumor stage in melanoma. Melanoma Res. 2015;25(6):479-85.
33 Matsumoto M, Kunimitsu S, Wada K, Ikeda M, Keyama A, Kodama H. Mast cell distribution, activation, and phenotype in xanthoma. J Am Acad Dermatol. 2007 Jun;56(6):1006-12.

34 Riekki R, Harvima IT, Jukkola A, Risteli J, Oikarinen A. The production of collagen and the activity of mast-cell chymase increase in human skin after irradiation therapy. Exp Dermatol. 2004 Jun;13(6):364-71.

35 Jouhilahti EM, Peltonen S, Callens T, Jokinen E, Heape AM, Messiaen L, et al. The development of cutaneous neurofibromas. Am J Pathol. 2011;178(2):500-5.

36 Rice FL, Houk G, Wymer JP, Gosline SJC, Guinney J, Wu J, et al. The evolution and multi-molecular properties of NF1 cutaneous neurofibromas originating from $\mathrm{C}$-fiber sensory endings and terminal Schwann cells at normal sites of sensory terminations in the skin. PLoS One. 2019;14(5):e0216527.

37 Feng-Chun Y, Ingram DA, Chen S, Hingtgen CM, Ratner N, Monk KR, et al. Neurofibromin-deficient Schwann cells secrete a potent migratory stimulus for $\mathrm{Nf} 1+/-$ mast cells. J Clin Invest. 2003 Dec;112(12):1851-61.

38 Chen S, Burgin S, McDaniel A, Li X, Yuan J, Chen M, et al. Nf1-/- Schwann cell-conditioned medium modulates mast cell degranulation by c-Kit-mediated hyperactivation of phosphatidylinositol 3-kinase. Am J Pathol. 2010;177(6):3125-32.

39 Liao CP, Booker RC, Brosseau JP, Chen Z, Mo J, Tchegnon E, et al. Contributions of inflammation and tumor microenvironment to neurofibroma tumorigenesis. J Clin Invest. 2018 Jul;128(7):2848-61.

40 Yang FC, Chen S, Clegg T, Li X, Morgan T, Estwick SA, et al. Nf1+/- mast cells induce neurofibroma like phenotypes through secreted TGF-beta signaling. Hum Mol Genet. 2006 Aug;15(16):2421-37.

41 Harvima IT, Levi-Schaffer F, Draber P, Friedman S, Polakovicova I, Gibbs BF, et al. Molecular targets on mast cells and basophils for novel therapies. J Allergy Clin Immunol. 2014;134(3):530-44. 